\title{
The moderating effect of solar radiation on the association between human mobility and COVID-19 infection in Europe
}

\author{
Wenyu Zhao ${ }^{1} \cdot$ Yongjian Zhu $^{1}$ (D) $\cdot$ Jingui Xie ${ }^{2} \cdot$ Zhichao Zheng $^{3} \cdot$ Haidong Luo $^{4} \cdot$ Oon Cheong Ooi ${ }^{4}$
}

Received: 6 April 2021 / Accepted: 27 July 2021 / Published online: 3 August 2021

(C) The Author(s), under exclusive licence to Springer-Verlag GmbH Germany, part of Springer Nature 2021

\begin{abstract}
The novel coronavirus disease 2019 (COVID-19) has caused a global pandemic. Some studies have suggested a negative association between sunlight intensity and COVID-19 infection, alluding to the belief that it might be safe to go out on sunny days. This paper examined whether solar radiation mitigated the association between human mobility and COVID-19 infection in Europe using a dynamic panel data model to investigate the effect of human mobility, solar radiation, and their interaction on COVID-19 infection. The results revealed that outgoing mobility was positively correlated and solar radiation was negatively correlated with COVID-19 infection at lag levels of 1,2, and 3 weeks. The coefficients of the interaction items indicated that solar radiation negatively moderated the relationship between outgoing mobility and the number of daily new confirmed cases at 2and 3-week lag levels. However, the moderating effect was limited and unable to eliminate the positive effect of outgoing mobility on COVID-19 infection. Thus, these results suggested that solar radiation only weakly mitigated the relationship between human mobility and COVID-19 infection, providing policy implications that mobility should still be restricted on sunny days during the COVID-19 pandemic.
\end{abstract}

Keywords Solar radiation $\cdot$ Human mobility $\cdot$ COVID-19 $\cdot$ Moderating effect

\section{Introduction}

Coronavirus disease 2019 (COVID-19), caused by severe acute respiratory syndrome coronavirus 2 , is a severe public health problem (Sohrabi et al., 2020). It first broke out in Wuhan City, China, in December 2019 (Lu et al. 2020). Despite local governments implementing consistent restriction measures, COVID-19 has become a global pandemic, and numerous countries are suffering from the contagion of COVID-19 (World Health Organization 2021).

Many studies (Kraemer et al. 2020; Xiong et al. 2020; Oztig and Askin 2020) have proven that the participation of people in outdoor activities plays an essential role in COVID19 transmission. Furthermore, human mobility was identified as a critical variable in the spread of COVID-19 infections (Cartenì et al. 2020). Because increased human mobility is positively correlated with COVID-19 transmission, lockdown

Responsible Editor: Lotfi Aley

Yongjian Zhu

ustczyj@mail.ustc.edu.cn

Wenyu Zhao

zhaowy8@mail.ustc.edu.cn

Jingui Xie

jingui.xie@tum.de

Zhichao Zheng

danielzheng@smu.edu.sg

Haidong Luo

hai_dong_luo@nuhs.edu.sg
Oon Cheong Ooi

oon_cheong_ooi@nuhs.edu.sg

1 School of Management, University of Science and Technology of China, Hefei, China

2 School of Management, Technical University of Munich, Heilbronn, Germany

3 Lee Kong Chian School of Business, Singapore Management University, Singapore, Singapore

4 Department of Cardiac, Thoracic \& Vascular Surgery, National University Hospital, Singapore, Singapore 
orders have been imposed by governments around the world during the outbreak (Cheng et al. 2020). However, these restrictions do not stop people from being more likely to go outside on sunny days (Paez et al. 2020; Azuma et al. 2020).

An increasing number of studies are investigating the association between sunlight and COVID-19 using a variety of measurements of sunlight, such as solar irradiance (Gupta et al. 2020; Bäcker 2020; Ahmadi et al. 2020), the ultraviolet index (Kalippurayil et al., 2020; Takagi et al. 2020), sunshine duration (Asyary and Veruswati 2020; Li et al. 2020a; Thangriyal et al. 2020), and latitude (Whittemore 2020). Although the results of these studies were somewhat inconsistent, most studies have shown that more sunlight is associated with reduced coronavirus infection (Carleton et al. 2021; Guasp et al. 2020; Thangriyal et al. 2020). Ultraviolet irradiation was reported to inactivate coronaviruses and reduce the viral load, thereby reducing coronavirus transmission (Bedell et al. 2016; Hamzavi et al. 2020). Additionally, sunlight exposure boosts the immune system by inducing vitamin D synthesis (Engelsen 2010; Wacker and Holick 2013; Holick 2017; Li et al. 2020b), which may help reduce the risk of COVID-19 infection (Grant et al. 2020; Ilie et al. 2020; Ebadi and Montano-Loza 2020; Xu et al. 2020). These findings could lead to some individuals and governments believing that it might be safe to go out on sunny days and thus tending to relax control measures when the local weather is sunny (The New York Times 2020; Matthews 2020; Robertson 2020; McGuinness 2021).

Although sunlight is negatively associated with COVID-19 transmission, it is unclear whether the association between human mobility and COVID-19 infection would be mitigated on sunny days. To this end, we investigated the moderating effect of sunlight on the association between human mobility and COVID-19 infection using data from 15 European countries. Our findings will contribute to address the misconception that it is safe to go outdoors on a sunny day, providing important implications for public health policymaking that weather conditions alone are insufficient to support lifting lockdown restrictions. Further contributing to the knowledge base of COVID-19 transmission, the study shows that in addition to a direct effect on viral transmission, solar radiation could also be helpful to control the pandemic by mitigating the association between human mobility and COVID-19 infection even if the moderating effect is limited.

\section{Materials and methods}

\section{Data collection}

We obtained our study data from Google Cloud Public Datasets (Wahltinez et al. 2020), including the numbers of daily new confirmed COVID-19 cases, mobility, and meteorological data (average temperature and rainfall) at the subregion level. Specifically, Google mobility data includes mobility information of individuals' visits to retail and recreation, groceries and pharmacies, parks, transit stations, workplaces, and residential. The data were constructed by Google by comparing visits and time spent in certain places to a baseline using information from Google Maps (Yilmazkuday 2021). Due to inconsistent trends, we excluded data on visits to parks and residences (Nouvellet et al. 2021). The start date of the mobility data was February 15, 2020. The moving average of the lag effect of human mobility for up to 21 days was calculated from data on COVID-19 cases collected after March 7, 2020. Then, we chose 3 months as the observation period (March 7-June 6, 2020) in this study.

Solar radiation data were obtained from the E-OBS daily gridded meteorological data (https://cds.climate.copernicus. $\mathrm{eu} /$ ), which provides daily gridded weather variables at a resolution of $0.25^{\circ} \times 0.25^{\circ}$ longitude in Europe. We linked the gridded weather data to the number of COVID-19 cases at the subregion level using BaiduMap SDK geocoder (https:// lbsyun.baidu.com/index.php?title=webapi/guide/webservicegeocoding) to obtain the grids' locations and averaged the grid data of each region to capture climatic conditions.

After merging and excluding subregions (province, state, or the local equivalent) with incomplete data, the final dataset included 178 subregions in 15 European countries between March 7 and June 6, 2020 (Fig. 1). The number of subregions covered in each country is detailed in Table S1.

\section{Measuring outgoing mobility}

Considering the high correlation between the four types of Google mobility (Table S2), we used principal component analysis to extract the common component as a new variable, named outgoing mobility to capture public outdoor mobility. The outgoing mobility of region $i$ on day $t$ was defined as follows:

$$
\begin{aligned}
\text { mobout }_{i t}= & 0.5159 \times \text { mobrr }_{i t}+0.4725 \times \text { mobgp }_{i t} \\
& +0.5148 \times \text { mobts }_{i t}+0.4955 \times \text { mobw }_{i t}
\end{aligned}
$$

where mobout $_{i t}$ is the outgoing mobility of region $i$ on day $t$; $m_{o b r r}{ }_{i t}, \operatorname{mobgp}_{i t}$, mobts $_{i t}$, and $m o b w_{i t}$ represent human mobility in retail and recreation, groceries and pharmacies, transit stations, and workplaces, respectively. All variables were standardized before input into Equation (1) (Singh and Harrison 1985). The weights of the four mobility variables in Equation (1) were obtained from the principal component analysis. mobout $_{i t}$ explained $85.69 \%$ of the variance of the initial variables. 
Fig. 1. Locations of 15 European countries and the cumulative number of confirmed new cases between 7 March and 6 June 2020 in the included subregions in each country.

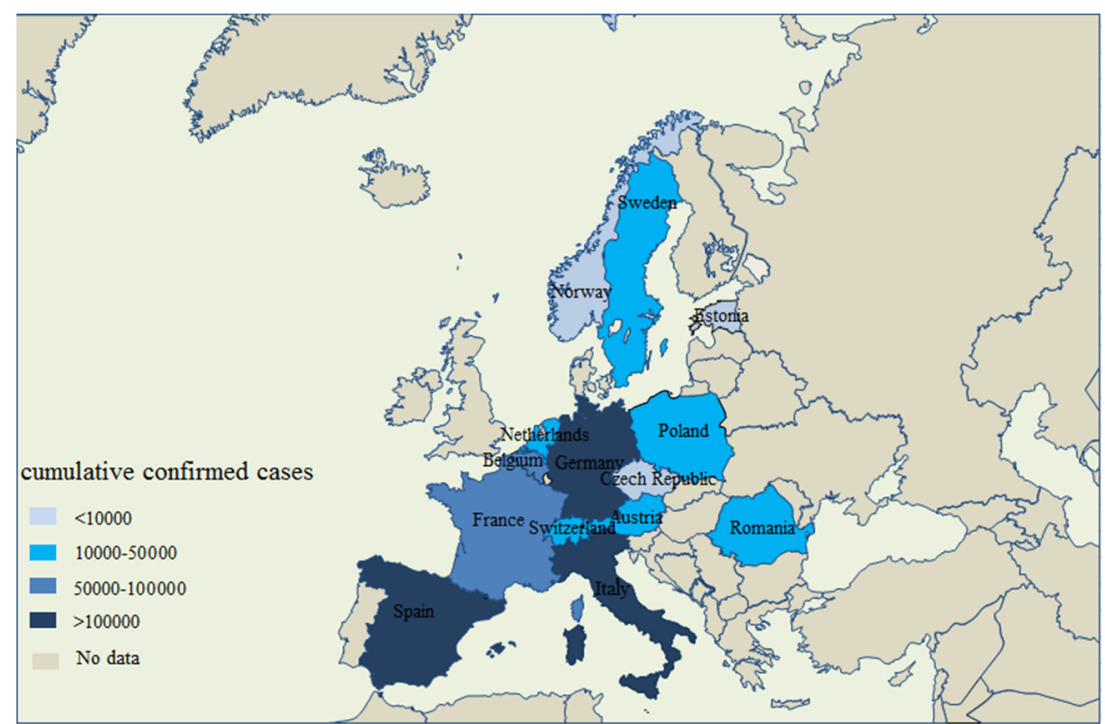

Our main analysis used outgoing mobility data to explore the association between outgoing mobility and COVID-19 infection as well as the moderating effect of solar radiation. In the additional analysis, we used mobility data for retail and recreation, groceries and pharmacies, transit stations, and workplaces, respectively, to test the moderating effect of solar radiation.

\section{Statistical analysis}

We used dynamic panel models to capture information on the partial adjustment mechanism of COVID-19 infections by adding lagged dependent variables to the model (Weinhold 1999; Leszczensky and Wolbring 2019). The most commonly used methods for estimating dynamic panel models are Arellano and Bond's (1991) difference generalized method of moments (GMM) and Blundell and Bond's (1998) system GMM. However, both perform poorly when the panel is characterized by a low number of individuals (Bogliacino et al. 2012). Thus, we used the least squares dummy variable corrected (LSDVC) estimator (Bruno 2005a), which performs well when the number of individuals is small and the panel is severely unbalanced (Bruno 2005b). Dang et al. (2015) found that the LSDVC estimator performs better for estimating dynamic panel data models in various experiments and empirical research when allowing for the presence of unobserved heterogeneity, endogeneity, and residual serial correlation. We also used the standard fixed effects estimation as a robustness check (Flannery and Hankins 2013).

Given the incubation period of COVID-19, we used a moving-average approach to account for the lag effect of solar radiation, human mobility, temperature, and rainfall (Xie and
Zhu 2020; Duan et al. 2019). There were two parts to our analysis. Firstly, we examined the association of COVID-19 infection with human mobility and solar radiation (Model 1) as follows:

$$
\begin{aligned}
Y_{i t}= & \alpha_{0}+\alpha_{1} Y_{i, t-1}+\alpha_{2} \text { solar }_{i t_{l}}+\alpha_{3} \text { mobility }_{i t_{l}} \\
& +\alpha_{4} \text { tem }_{i t_{l}}+\alpha_{5} \text { rain }_{i t_{l}}+\eta_{t}+\mu_{i}+\varepsilon_{i t}
\end{aligned}
$$

where $t$ is the date and $i$ is the subregion; $Y_{i t}$ is the daily number of new confirmed COVID-19 cases; solar $_{i t_{l}}$ and mobility $_{i t_{l}}$ represent the $(l+1)$-day moving average term $(\operatorname{lag} 0-l)$ of solar radiation and human mobility in the region $i$ (we considered three lag levels: 1 week, $l=7 ; 2$ weeks, $l=14$; and 3 weeks, $l=21$ ), respectively; $t e m_{i t_{l}}$ and $\operatorname{rain}_{i t_{l}}$ are the average temperature and rainfall during the same period, respectively; $\eta_{t}$ is the day fixed effects; $\mu_{i}$ is the unobserved subregion-specific effect; $\varepsilon_{i t}$ is the regression residual; $\alpha_{0}$ is the intercept; and $\alpha_{1}, \alpha_{2}, \alpha_{3}, \alpha_{4}$ and $\alpha_{5}$ are the corresponding coefficients.

Next, we explored whether solar radiation moderates the relationship between human mobility and COVID-19 infection using Model 2 (Equation (3)). The variables were centered before the interaction term was calculated to avoid multicollinearity (Zheng et al. 2021). The model was expressed as follows:

$$
\begin{aligned}
Y_{i t}= & \beta_{0}+\beta_{1} Y_{i, t-1}+\beta_{2} \text { solar }_{i t_{l}}+\beta_{3} \text { mobility }_{i t_{l}} \\
& +\beta_{4} \text { solar }_{i t_{l}} \times \text { mobility }_{i_{l}}+\beta_{5} \text { tem }_{i t_{l}}+\beta_{6} \text { rain }_{i t_{l}} \\
& +\eta_{t}+\mu_{i}+\varepsilon_{i t}
\end{aligned}
$$

where $\beta_{0}$ is the intercept and $\beta_{1}, \beta_{2}, \beta_{3}, \beta_{4}$, and $\beta_{5}$ are the corresponding coefficients. 
Table 1 Descriptive statistics of COVID-19 patients, meteorological variables, and outgoing mobility

\begin{tabular}{lllll}
\hline Variable & Mean & Std.Dev. & Min & Max \\
\hline Daily new confirmed cases & 65.700 & 188.127 & 0 & 3251 \\
Solar radiation $\left(\mathrm{W} / \mathrm{m}^{2}\right)$ & 235.410 & 65.770 & 15.925 & 415.9 \\
Average temperature $\left({ }^{\circ} \mathrm{C}\right)$ & 11.235 & 5.117 & -9.844 & 26.104 \\
Rainfall $(\mathrm{mm})$ & 1.409 & 3.377 & 0 & 47.171 \\
Outgoing mobility & -0.650 & 1.574 & -4.623 & 5.006 \\
\hline
\end{tabular}

Std.Dev. standard deviation

\section{Results}

\section{Descriptive analysis}

Table 1 presents the descriptive statistics for meteorological variables, daily numbers of COVID-19 patients, and outgoing mobility. Over 923,000 confirmed COVID-19 cases were included in our study. The average daily number of new confirmed cases was 65.7 (maximum: 3,251). The average daily mean solar radiation level was $235.410 \mathrm{~W} / \mathrm{m}^{2}$ (minimum: $15.925 \mathrm{~W} / \mathrm{m}^{2}$ ). The average daily mean temperature and rainfall were $11.235^{\circ} \mathrm{C}$ and $1.409 \mathrm{~mm}$, respectively.

Table 2 shows the Spearman correlation coefficients between meteorological variables and mobility. Outgoing mobility was positively correlated with solar radiation, temperature, and rainfall.

\section{Estimation results of multivariate regression}

Columns (1), (3), and (5) in Table 3 show the moving average lag effects (lag0-7, lag0-14, and lag0-21) of outgoing mobility and solar radiation on COVID-19 infection according to Equation (2). Outgoing mobility was positively associated with the number of daily new confirmed COVID-19 cases. A unit increase in outgoing mobility was associated with increases of 3.898 (95\% confidence interval [CI]: 0.553-7.242), 6.922 (95\% CI: $3.016-10.827)$, and 8.557 (4.736-12.378) in the number of daily new confirmed COVID-19 cases for lag0-7, lag0-14, and lag0-21, respectively.
Solar radiation was negatively correlated with the number of daily new confirmed COVID-19 cases at all three lag levels, indicating a negative association between solar radiation and COVID-19 transmission. The lag effect on COVID19 infection of $1 \mathrm{~W} / \mathrm{m}^{2}$ of solar radiation was $-0.065(95 \% \mathrm{CI}$ : -0.104 to -0.026$)$ at $\operatorname{lag} 0-7,-0.087$ (95\% CI: -0.133 to $-0.041)$ at lag0-14, and -0.111 (95\% CI: -0.162 to -0.059$)$ at lag0-21. Thus, it was possible that high levels of solar radiation protected patients from COVID-19 infection.

Further analyses investigated the interactive impact of solar radiation and outgoing mobility. Interaction items of solar radiation and outgoing mobility were introduced in columns (2), (4), and (6) in Table 3. The interaction items were significantly and negatively correlated at the subregion level with new confirmed cases at lag0-14 and lag0-21. Fig. 2 depicts how solar radiation moderated the relationship between outgoing mobility and COVID-19 infection and suggests that high levels of solar radiation helped to mitigate the increased risk of outgoing mobility for COVID-19 infection. However, the interacting impact was too small to eliminate the risk of infection from going outside, and there was still a positive association between outgoing mobility and COVID-19 infection, even when exposed to high levels of solar radiation. The robustness checks showed similar results (Table S3).

Additional analyses using mobility data for retail and recreation, groceries and pharmacies, transit stations, and workplaces to separately test the moderating effect of solar radiation on the relationship between mobility and COVID-19 infection (Fig. S1-S4) also revealed a feeble association.

\section{Discussion}

We explored the moderating effect of solar radiation on the relationship between human mobility and COVID-19 infection in Europe using data on new confirmed cases from 178 subregions (province, state, or local equivalent) in 15 countries from March 7-June 6, 2020.

We found a significant negative correlation between solar radiation and confirmed new COVID-19 at all three lag levels, which was consistent with most previous studies ( $\mathrm{Li}$ et al. 2020a; Guasp et al. 2020; Thangriyal et al. 2020). Solar radiation might help to reduce the likelihood of transmission by
Table 2 Spearman correlation coefficients among meteorological variables and outgoing mobility

\begin{tabular}{lllll}
\hline & Solar radiation & Average temperature & Rainfall & Outgoing mobility \\
\hline Solar radiation & 1 & & & \\
Average temperature & $0.249 * * *$ & 1 & 1 & \\
Rainfall & $0.050^{* * *}$ & $-0.075^{* * *}$ & $0.046^{* * * *}$ & 1 \\
Outgoing mobility & $0.048^{* * *}$ & $0.055^{* * *}$ & \\
\hline
\end{tabular}

Level of significance: $* * * 1 \%, * * 5 \%, * 10 \%$. 


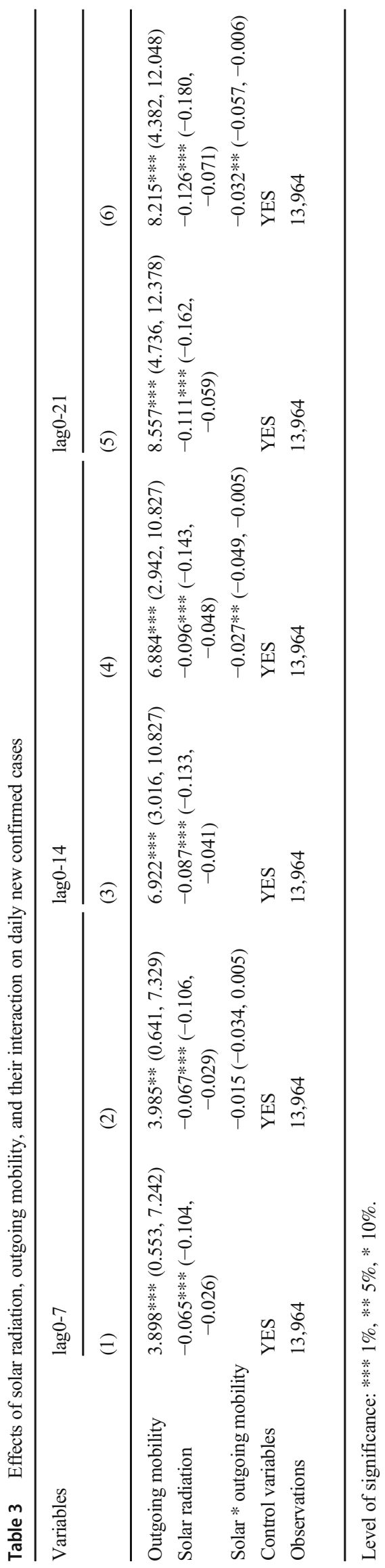

inactivating viruses (Carvalho et al. 2021; Sagripanti and Lytle 2020; Biasin et al. 2021). Additionally, exposure to solar radiation, mainly through outdoor activities, plays another protective role via vitamin D synthesis in the skin (Adams et al. 1982; Kimlin 2008; Engelsen 2010). Recent clinical studies have confirmed the association between vitamin D deficiency and COVID-19 incidence (Meltzer et al. 2020; Ali 2020; Luo et al. 2021). However, some studies also reported that sunshine duration (Asyary and Veruswati 2020) or solar radiation (Yao et al. 2020; Ahmadi et al. 2020) was not associated with the incidence of COVID-19 infection. Notably, because the inactivating effect of sunlight on COVID-19 may not be immediate, the lag effect of sunlight might have been overlooked in these studies. We found that outgoing mobility was positively correlated with the number of new confirmed cases at all three lag levels, consistent with previous studies (Kraemer et al. 2020; Xiong et al. 2020; Oztig and Askin 2020; Cartenì et al. 2020) and our conjecture.

Our results also demonstrated the negative moderating effect of solar radiation at 2- and 3-week lag levels, providing evidence that solar radiation could mitigate the relationship between human mobility and COVID-19 infection in Europe. This was probably because high levels of solar radiation would be more conducive to inactivating coronaviruses and reducing the viral load, thereby weakening coronavirus transmission (Ratnesar-Shumate et al. 2020) and reducing the likelihood of COVID-19 infection caused by outgoing mobility. However, coronavirus replication is exceptionally rapid (Chu et al. 2020), and most viruses spread under conditions where they are not typically exposed to sunlight or where they receive insufficient sunlight exposure to result in inactivation. Therefore, we concluded that the moderating effect of solar radiation was too weak to eliminate the correlation between outgoing mobility and COVID-19 infection. These findings contribute to the literature on the association of environmental factors and COVID-19 transmission, such as temperature (Xie and Zhu 2020; Ma et al. 2020; Shahzad et al. 2020a, b; Iqbal et al. 2020; Doğan et al. 2020), humidity (Liu et al. 2020; Fareed et al. 2020; Doğan et al. 2020), and air pollution (Zhu et al., 2020; Shakoor et al. 2020; Fareed et al. 2020; Shahzad et al. 2020b; Doğan et al. 2020). We have provided new evidence that besides the direct effect on virus transmission, solar radiation could also be helpful to control the pandemic by mitigating the association between human mobility and COVID-19 infection.

This study provides several policy implications for governments and the public. First, governments should not relax human mobility restrictions based solely on weather conditions (e.g., moving into summer) because solar radiation only weakly mitigates the relationship between human mobility and COVID-19 infection. For citizens, although the exposure to more sunlight boosts the immune system, public mobility outdoors carries a risk of infection, even on sunny days. 

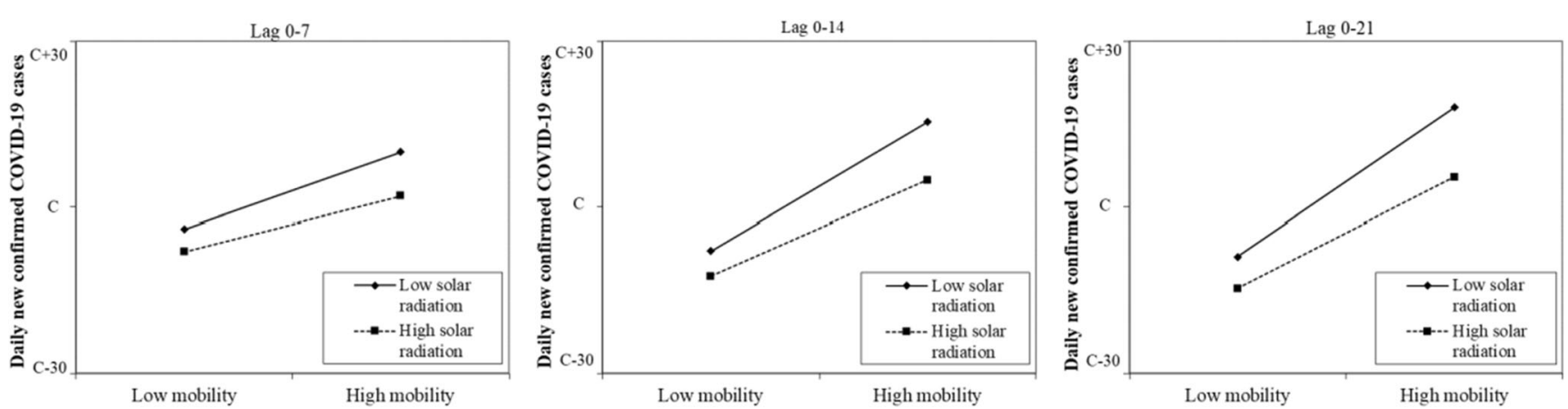

Fig. 2. The moderating effect of solar radiation on the relationship between outgoing mobility and COVID-19 infection. $C$ represents the constant term in Equation (3). High (low) solar radiation/mobility represents one standard deviation above (below) the mean.

Overall, we recommended that people are exposed to more sunlight without increasing outdoor mobility, such as on their balconies or in their gardens. Recently, the relative control of the COVID-19 pandemic with increasing levels of vaccinations has resulted in many countries gradually lifting their lockdown restrictions. We recommend that outdoor activities are opened first and the reopening of some indoor activities, such as restaurants, be moved outside during the daytime as much as possible.

There are several limitations to our study. Firstly, we analyzed the number of daily reported new cases, which might differ from the actual numbers. Secondly, the human mobility data were only obtained from Google. Although it might well approximate the overall mobility level in each region, the numbers could be biased because Google could not capture all the mobility. Thirdly, we only focused on the association, not the causal effect, and there could be endogeneity issues caused by unidentified confounders associated with this observational study.

\section{Conclusion}

We found a positive correlation between outgoing mobility and COVID-19 infection and a negative correlation between solar radiation and COVID-19 infection. Additionally, the influence of outgoing mobility on COVID-19 transmission decreased with increased levels of solar radiation at 2- and 3week lag levels. However, such a moderating effect was unable to eliminate the association of outgoing mobility with COVID-19 infection. Our findings correct the misconception that it is safe to go out on a sunny day, providing policy implications that lifting lockdown measures on sunny days is inappropriate. However, considering that the pandemic has been relatively controlled with vaccinations and many countries have relaxed lockdown restrictions, it is recommended that some indoor activities, such as reopening restaurants, be moved outside during the daytime as much as possible.
Supplementary Information The online version contains supplementary material available at https://doi.org/10.1007/s11356-021-15738-w.

Availability of data and materials The datasets used and/or analyzed during the current study are available from the corresponding author on reasonable request.

Author contribution Wenyu Zhao: data curation, writing (original draft preparation), visualization, and investigation.

Yongjian Zhu: validation and writing - reviewing and editing.

Jingui Xie: conceptualization, reviewing, and supervision.

Zhichao Zheng: methodology, supervision, and writing - reviewing and editing.

Haidong Luo: supervision, reviewing, and validation.

Oon Cheong Ooi: supervision, reviewing, and validation.

Funding This research was supported by the National Natural Science Foundation of China (NSFC) with grant Nos: 71921001 and 71571176 and by the Ministry of Education, Singapore, under its Academic Research Fund (AcRF) Tier 2 (Grant No. MOE2019-T2-1-185).

\section{Declarations}

Ethics approval and consent to participate Not applicable.

Consent for publication Not applicable.

Conflict of interests The authors declare no competing interests.

\section{References}

Adams JS, Clemens TL, Parrish JA, Holick MF (1982) Vitamin-D synthesis and metabolism after ultraviolet irradiation of normal and vitamin-D-deficient subjects. N Engl J Med 306(12):722-725

Ahmadi M, Sharifi A, Dorosti S, Ghoushchi SJ, Ghanbari N (2020) Investigation of effective climatology parameters on COVID-19 outbreak in Iran. Sci Total Environ 729:138705

Ali N (2020) Role of vitamin D in preventing of COVID-19 infection, progression and severity. J Infect Public Health 13(10):1373-1380

Arellano M, Bond S (1991) Some tests of specification for panel data: Monte Carlo evidence and an application to employment equations. Rev Econ Stud 58(2):277-297

Asyary A, Veruswati M (2020) Sunlight exposure increased Covid-19 recovery rates: a study in the central pandemic area of Indonesia. Sci Total Environ 729:139016 
Azuma K, Kagi N, Kim H, Hayashi M (2020) Impact of climate and ambient air pollution on the epidemic growth during COVID-19 outbreak in Japan. Environ Res 190:110042

Bäcker A (2020) Slower COVID-19 morbidity and mortality growth at higher solar irradiance and elevation. SSRN. https://ssrn.com/ abstract $=3604729$

Bedell K, Buchaklian AH, Perlman S (2016) Efficacy of an automated multiple emitter whole-room ultraviolet-C disinfection system against coronaviruses MHV and MERS-CoV. Infect Control Hosp Epidemiol 37(5):598-599

Biasin M, Bianco A, Pareschi G, Cavalleri A, Cavatorta C, Fenizia C, Galli P, Lessio L, Lualdi M, Tombetti E, Ambrosi A, Redaelli E, Saulle I, Trabattoni D, Zanutta A, Clerici M (2021) UV-C irradiation is highly effective in inactivating SARS-CoV-2 replication. Scientif Rep 11(1): 6260

Blundell R, Bond S (1998) Initial conditions and moment restrictions in dynamic panel data models. J Econ 87(1):115-143

Bogliacino F, Piva M, Vivarelli M (2012) R\&D and employment: an application of the LSDVC estimator using European microdata. Econ Lett 116(1):56-59

Bruno GS (2005a) Approximating the bias of the LSDV estimator for dynamic unbalanced panel data models. Econ Lett 87(3):361-366

Bruno GS (2005b) Estimation and inference in dynamic unbalanced panel-data models with a small number of individuals. Stata J 5(4):473-500

Carleton T, Cornetet J, Huybers P, Meng KC, Proctor J (2021) Global evidence for ultraviolet radiation decreasing COVID-19 growth rates. Proc Natl Acad Sci 118(1):e2012370118

Cartenì A, Di Francesco L, Martino M (2020) How mobility habits influenced the spread of the COVID-19 pandemic: results from the Italian case study. Sci Total Environ 741:140489

Carvalho FR, Henriques DV, Correia O, Schmalwieser AW (2021) Potential of solar UV radiation for inactivation of coronaviridae family estimated from satellite data. Photochem Photobiol 97(1): 213-220

Cheng C, Barceló J, Hartnett AS, Kubinec R, Messerschmidt L (2020) COVID-19 government response event dataset (CoronaNet v. 1.0). Nat Hum Behav 4(7):756-768

Chu H, Chan JFW, Yuen TTT, Shuai H, Yuan S, Wang Y, Hu B, Yip CCY, Tsang JOL, Huang X, Chai Y, Yang D, Hou Y, Chik KKH, Zhang X, Fung AYF, Tsoi HW, Cai JP, Chan WM, Ip JD, Chu AWH, Zhou J, Lung DC, Kok KH, To KKW, Tsang OTY, Chan KH, Yuen KY (2020) Comparative tropism, replication kinetics, and cell damage profiling of SARS-CoV-2 and SARS-CoV with implications for clinical manifestations, transmissibility, and laboratory studies of COVID-19: an observational study. Lancet Microbe 1(1):e14-e23

Dang VA, Kim M, Shin Y (2015) In search of robust methods for dynamic panel data models in empirical corporate finance. J Bank Financ 53:84-98

Doğan B, Jebli MB, Shahzad K, Farooq TH, Shahzad U (2020) Investigating the effects of meteorological parameters on COVID19: case study of New Jersey, United States. Environ Res 191: 110148

Duan Y, Liao Y, Li H, Yan S, Zhao Z, Yu S, Fu Y, Wang Z, Yin P, Cheng J, Jiang H (2019) Effect of changes in season and temperature on cardiovascular mortality associated with nitrogen dioxide air pollution in Shenzhen, China. Sci Total Environ 697:134051

Ebadi M, Montano-Loza AJ (2020) Perspective: improving vitamin D status in the management of COVID-19. Eur J Clin Nutr 74(6): $856-859$

Engelsen O (2010) The relationship between ultraviolet radiation exposure and vitamin D status. Nutrients 2(5):482-495

Fareed Z, Iqbal N, Shahzad F, Shah SGM, Zulfiqar B, Shahzad K, Hashmi SH, Shahzad U (2020) Co-variance nexus between COVID-19 mortality, humidity, and air quality index in Wuhan,
China: new insights from partial and multiple wavelet coherence. Air Qual Atmos Health 13:673-682

Flannery MJ, Hankins KW (2013) Estimating dynamic panel models in corporate finance. J Corp Finan 19:1-19

Grant WB, Lahore H, McDonnell SL, Baggerly CA, French CB, Aliano JL, Bhattoa HP (2020) Evidence that vitamin D supplementation could reduce risk of influenza and COVID-19 infections and deaths. Nutrients 12(4):988

Guasp M, Laredo C, Urra X (2020) Higher solar irradiance is associated with a lower incidence of coronavirus disease 2019. Clin Infect Dis 71(16):2269-2271

Gupta A, Banerjee S, Das S (2020) Significance of geographical factors to the COVID-19 outbreak in India. Model Earth Syst Environ 6(4): 2645-2653

Hamzavi IH, Lyons AB, Kohli I, Narla S, Parks-Miller A, Gelfand JM, Lim HW, Ozog DM (2020) Ultraviolet germicidal irradiation: possible method for respirator disinfection to facilitate reuse during the COVID-19 pandemic. J Am Acad Dermatol 82(6):1511-1512

Holick MF (2017) Ultraviolet B Radiation: The Vitamin D Connection. Adv Exp Med Biol 996:137-154

Ilie PC, Stefanescu S, Smith L (2020) The role of vitamin D in the prevention of coronavirus disease 2019 infection and mortality. Aging Clin Exp Res 32(7):1195-1198

Iqbal N, Fareed Z, Shahzad F, He X, Shahzad U, Lina M (2020) The nexus between COVID-19, temperature and exchange rate in Wuhan city: new findings from partial and multiple wavelet coherence. Sci Total Environ 729:138916

Kimlin MG (2008) Geographic location and vitamin D synthesis. Mol Asp Med 29(6):453-461

Kraemer MU, Yang CH, Gutierrez B, Wu CH, Klein B, Pigott DM et al (2020) The effect of human mobility and control measures on the COVID-19 epidemic in China. Science 368(6490):493-497

Leszczensky L, Wolbring T (2019) How to deal with reverse causality using panel data? Recommendations for researchers based on a simulation study. Sociol Methods Res. https://doi.org/10.1177/ 0049124119882473

Li H, Xu XL, Dai DW, Huang ZY, Ma Z, Guan YJ (2020a) Air pollution and temperature are associated with increased COVID-19 incidence: a time series study. Int $\mathrm{J}$ Infect Dis 97:278-282

Li Y, Li Q, Zhang N, Liu Z (2020b) Sunlight and vitamin D in the prevention of coronavirus disease (COVID-19) infection and mortality in the United States. Research Square. https://doi.org/10. 21203/rs.3.rs-32499/v1

Liu J, Zhou J, Yao J, Zhang X, Li L, Xu X, He X, Wang B, Fu S, Niu T, Yan J, Shi Y, Ren X, Niu J, Zhu W, Li S, Luo B, Zhang K (2020) Impact of meteorological factors on the COVID-19 transmission: a multi-city study in China. Sci Total Environ 726:138513. Advance online publication. https://doi.org/10.1016/j.scitotenv.2020.138513

Lu H, Stratton CW, Tang YW (2020) Outbreak of pneumonia of unknown etiology in Wuhan, China: the mystery and the miracle. $\mathrm{J}$ Med Virol 92(4):401-402

Luo X, Liao Q, Shen Y, Li H, Cheng L (2021) Vitamin D deficiency is inversely associated with covid-19 incidence and disease severity in Chinese people. J Nutr 151(1):98-103

Ma Y, Zhao Y, Liu J, He X, Wang B, Fu S, Yan J, Niu J, Zhou J, Luo B (2020) Effects of temperature variation and humidity on the death of COVID-19 in Wuhan, China. Sci Total Environ 724:138226

Matthews C (2020) Trump says coronavirus could be thwarted by summer heat, citing DHS study. MarketWatch. https://www. marketwatch.com/story/trump-says-coronavirus-could-bethwarted-by-summer-heat-citing-dhs-study-2020-04-23. Accessed 26 May 2021

McGuinness A (2021) COVID-19: face masks may not be needed indoors over summer, deputy chief medical officer suggests. Sky News. https://news.sky.com/story/covid-19-face-masks-may-not- 
be-needed-indoors-over-summer-deputy-chief-medical-officersuggests-12227958. Accessed 26 May 2021

Meltzer DO, Best TJ, Zhang H, Vokes T, Arora V, Solway J (2020) Association of vitamin D status and other clinical characteristics with COVID-19 test results. JAMA Netw Open 3(9):e2019722e2019722

Nouvellet P, Bhatia S, Cori A, Ainslie KE, Baguelin M, Bhatt S et al (2021) Reduction in mobility and COVID-19 transmission. Nat Commun 12(1):1-9

Oztig LI, Askin OE (2020) Human mobility and coronavirus disease 2019 (COVID-19): a negative binomial regression analysis. Public Health 185:364-367

Paez A, Lopez FA, Menezes T, Cavalcanti R, Pitta M (2020) A SpatioTemporal Analysis of the Environmental Correlates of COVID-19 Incidence in Spain. Geogr Anal. Advance online publication. https:// doi.org/10.1111/gean.12241

Ratnesar-Shumate S, Williams G, Green B, Krause M, Holland B, Wood S, Bohannon J, Boydston J, Freeburger D, Hooper I, Beck K, Yeager J, Altamura LA, Biryukov J, Yolitz J, Schuit M, Wahl V, Hevey M, Dabisch P (2020) Simulated sunlight rapidly inactivates SARS-CoV-2 on surfaces. J Infect Dis 222(2):214-222

Robertson C (2020) Coronavirus: nine times Jair Bolsonaro dismissed the severity of COVID-19. Sky News. https://news.sky.com/story/ coronavirus-nine-times-jair-bolsonaro-dismissed-the-severity-ofcovid-19-12023297. Accessed 26 May 2021

Sagripanti JL, Lytle CD (2020) Estimated inactivation of coronaviruses by solar radiation with special reference to COVID-19. Photochem Photobiol 96(4):731-737

Shahzad F, Shahzad U, Fareed Z, Iqbal N, Hashmi SH, Ahmad F (2020a) Asymmetric nexus between temperature and COVID-19 in the top ten affected provinces of China: a current application of quantile-onquantile approach. Sci Total Environ 736:139115

Shahzad K, Shahzad U, Iqbal N, Shahzad F, Fareed Z (2020b) Effects of climatological parameters on the outbreak spread of COVID-19 in highly affected regions of Spain. Environ Sci Pollut Res 27(31): 39657-39666

Shakoor A, Chen X, Farooq TH, Shahzad U, Ashraf F, Rehman A, Sahar N, Yan W (2020) Fluctuations in environmental pollutants and air quality during the lockdown in the USA and China: two sides of COVID-19 pandemic. Air Qual Atmos Health 13(11):1335-1342

Singh A, Harrison A (1985) Standardized principal components. Int J Remote Sens 6(6):883-896

Takagi H, Kuno T, Yokoyama Y, Ueyama H, Matsushiro T, Hari Y, Ando T (2020) Higher air temperature, pressure, and ultraviolet are associated with less COVID-19 incidence. medRxiv. https:// doi.org/10.1101/2020.05.09.20096321

Thangariyal S, Rastogi A, Tomar A, Bhadoria AS, Baweja S (2020) Impact of temperature and sunshine duration on daily new cases and death due to COVID-19. J Family Med Prim Care 9(12): 6091-6101

The New York Times (2020) Relaxed Rules and Warm Weather Test States. https://www.nytimes.com/2020/05/02/us/coronavirusupdates.html. Accessed 26 May 2021

Wacker M, Holick MF (2013) Sunlight and Vitamin D: a global perspective for health. Dermato-endocrinology 5(1):51-108

Wahltinez O, Murphy K, Brenner M, Lee M, Erlinger A, Daswani M, Yawalkar P, Ontiveros Z, Alcantara R, Cheung D, Cheung A, Nath C, Le P, Navarro OP (2020) COVID-19 Open-Data: curating a finegrained, global-scale data repository for SARS-CoV-2, https://goo. gle/covid-19-open-data. Work in progress. Accessed 23 January 2021

Weinhold D (1999) A dynamic fixed effects model for heterogeneous panel data. London School of Economics. Mimeo, London

Whittemore PB (2020) COVID-19 fatalities, latitude, sunlight, and vitamin D. Am J Infect Control 48(9):1042-1044

World Health Organization (2021) Coronavirus disease (COVID-19) Weekly Epidemiological Update and Weekly Operational Update. https://www.who.int/emergencies/diseases/novel-coronavirus2019/situation-reports. Accessed 26 May 2021

Xie J, Zhu Y (2020) Association between ambient temperature and COVID-19 infection in 122 cities from China. Sci Total Environ 724:138201

Xiong C, Hu S, Yang M, Luo W, Zhang L (2020) Mobile device data reveal the dynamics in a positive relationship between human mobility and COVID-19 infection. Proc Natl Acad Sci 117(44):2708727089

Xu Y, Baylink DJ, Chen CS, Reeves ME, Xiao J, Lacy C, Cao H (2020) The importance of vitamin d metabolism as a potential prophylactic, immunoregulatory and neuroprotective treatment for COVID-19. J Translat Med 18(1):1-12

Yao Y, Pan J, Liu Z, Meng X, Wang W, Kan H, Wang W (2020) No association of COVID-19 transmission with temperature or UV radiation in Chinese cities. Eur Respir J 55(5):2000517

Yilmazkuday H (2021) Stay-at-home works to fight against COVID-19: international evidence from Google mobility data. J Human Behav Soc Environ 31(1-4): 210-220

Zheng S, Wang R, Mak TM, Hsu SC, Tsang DC (2021) How energy service companies moderate the impact of industrialization and urbanization on carbon emissions in China? Sci Total Environ 751: 141610

Publisher's note Springer Nature remains neutral with regard to jurisdictional claims in published maps and institutional affiliations. 